SHORT REPORT:

\title{
Enhancing intergroup communication in healthcare: The role of the receiver
}

\author{
M. Barlow
}

\begin{abstract}
This paper explores how the communication behaviour of another can have significant personal and professional impact and, in turn, put others in harm's way. In healthcare, in a continual attempt to address known barriers to communication, such as fear, hierarchy and power differentials, significant human and financial resources are deployed to develop and teach new and existing methods of how to speak up. Despite the effort, speaking up remains difficult, and as a result, patients are still being harmed. The author's personal story highlights the fact that maybe, until now, we have not been addressing the whole issue.
\end{abstract}

Keywords: speaking up; receiver; healthcare; communication behaviour; communication failure; healthcare communication; voice

\section{Background}

One morning, similar to many others, there was a large multidisciplinary ward round in the intensive care unit (ICU). As the bedside nurse, I knew one patient was not ready to come off the ventilator. I spoke up and, to the best of my ability, tried to explain my concerns to the senior medical consultant and nine other multidisciplinary colleagues. The senior medical consultant shouted orders to take the patient off the ventilator and dismissed my apprehensions. As a more junior clinician, I felt put in my place. After the incident, I spoke in private to the registrar, who confided that he agreed with my assessment of the patient. Unfortunately, he chose not to speak up because he had applied for an ICU training position, and the senior medical consultant had the deciding vote

School of Psychology, University of Queensland

School of Nursing, Midwifery and Paramedicine, Australian Catholic University

\section{Correspondence}

Melanie Barlow

School of Nursing, Midwifery and Paramedicine

Australian Catholic University

1100 Nudgee Rd

Banyo, QLD 4014

Tel: +61736236391 or +61738617276

Email: melanie.barlow@uqconnect.edu.au 
and, therefore, some control over the registrar's future. Since the registrar felt he couldn't speak up, we had to find another way to protect the patient. With only minutes before the senior consultant was due to return, we administered a number of medications that we hoped would reduce the amount of fluid the patient was retaining and proceeded to take her off the ventilator as ordered. The patient deteriorated rapidly, requiring active resuscitation. Whilst the patient was being resuscitated, the senior consultant walked through the door yelling, "What the hell are you doing!"

Fortunately, the patient survived, although I am unaware of the long-term health impacts the decision had on her. I do know the long-term impact the decision has had on me, both personally and professionally. At the time, I knew it was critical to speak up, to have a voice and to be heard, yet I felt powerless because of how my message was received. Although there are many definitions, I consider "speaking up" in healthcare as explicit communication that challenges the status quo and is maintained until resolution is achieved to prevent error and harm (physical and/or psychological) to staff and patients. In the above example, there was no resolution, and the result was patient harm. When a receiver of communication responds in the manner I encountered, it is easy to see how the person speaking up might negatively evaluate the interaction and how it might influence future encounters.

\section{Communication in healthcare}

My story is not an uncommon one. Medical error is now the third highest cause of death in the United States, with failures in communication being a proven contributing factor (Makary \& Daniel, 2016). Ineffective speaking up is a significant subset of communication failures in healthcare. Voicing concerns, or speaking up, is a complex process with a number of well-documented barriers, such as fear of retribution, appearing vulnerable, uncertainty about whether the concern is justified, futility and the unpredictability of how the message will be received (A. Jones et al., 2021). When such barriers are present, choosing whether to voice a concern or remain silent is determined by whether a person feels psychologically safe, in that moment, to take the interpersonal risk (Edmondson et al., 2016). The receiver plays an important role in enhancing the psychological safety of not only the sender but also any individual who witnesses the interaction.

Many healthcare training programs teach participants the technical skills of speaking up in the presence of these barriers, so why is it still so hard? Unfortunately, learning to speak up is not as simple as remembering a rubric or passing a competency. Healthcare communication is a dynamic and complex process that occurs at an interpersonal (personto-person) level but is impacted by the situational context and often received, and most likely perceived, from an intergroup perspective. 


\section{Intergroup communication}

Healthcare is steeped in traditional hierarchical structures and is notoriously intergroup by nature, which has been demonstrated to impact healthcare communication (for example, L. Jones et al., 2018). There are intergroup dynamics (different professions and the status of the different professions) and within-group dynamics (subspecialties and hierarchy within the same profession). The clinical training environment is even reliant on the hierarchical structure, with senior healthcare professionals supervising junior professionals and career advancement dependent on these hierarchical relationships. There is extensive literature on the impact hierarchy and the perceived or actual power differentials in healthcare have on speaking-up and employee voice behaviour (A. Jones et al., 2021). Despite this knowledge and helpful interventions designed to flatten hierarchies in these critical conversations, such as leader inclusiveness (Edmondson et al., 2016), speaking up remains difficult and patients are still being harmed.

The key contributing factor in the example I described was hierarchy, both from an intergroup status perspective (nursing is traditionally perceived as lower status than medicine) and from a seniority perspective (junior clinician to senior clinician). Although the interaction was between two people (interpersonal), it was actually an intergroup communication encounter, as professional group identity (nurse speaking up to a doctor) was most salient in that moment. Social identity theory (SIT) (Tajfel, 1974) explains how individuals favour their in-groups (those groups to which they belong) and discriminate against out-groups (groups to which they do not belong). SIT theorises that an individual is motivated to make their own group (in-group) positively distinct from others. This behaviour aims to maintain professional group status and prestige and maintain social distance from the professional out-group (Tajfel, 1974). The hierarchical intergroup dynamic impacts communication behaviour of both the sender and the receiver within speaking-up encounters. Individuals will adjust their behaviour depending on their conversational partner and the context in which the communication is occurring.

Through my experience as a clinician attending speaking-up training programs and as an educator developing them, I am familiar with the aims of these programs focused on teaching people to speak up. They include what to say and how and when to say it, regardless of who the conversational interactants are or the conversational context. The literature on speaking-up training programs acknowledges the hierarchical nature of healthcare as a barrier, but programs have not been developed that actively include and tangibly address the intergroup dynamics and how communication is affected by status and context. Healthcare training programs have been teaching one person in the conversation how to communicate effectively by using frameworks (e.g., CUSS and the two-challenge rule) that are applied irrespective of the clinical context or the conversational partner and have predominately left the receiver of the speaking-up message mostly unaccountable and untrained. 


\section{Role of the receiver}

The role of the receiver is a crucial element to many communication models, highlighting the importance of both the sender's and receiver's ability to send, hear and understand a message. The models suggest that there are many influencing factors affecting both communication interactants, such as communication skills, attitude toward each other (including status), content of the message and level of understanding and knowledge of the subject in discussion, social background, situational context and culture (Oyero, 2010).

Receiving of a message within a feedback conversational context is not a novelty within certain healthcare contexts, such as clinical supervision. However, the concept of the receiver within the clinical speaking-up conversational context has been significantly under researched and inadequately applied. The lessons learned from the feedback literature highlight a number of barriers to receiving feedback that can be generalised to speaking-up conversations, such as activation of emotions, ability to listen, perceived level of credibility of the sender and the existing relationship with the sender (Stone \& Heen, 2015). One key difference between feedback and speaking up is that feedback can occur in protected and agreed upon timeframes, whereas speaking-up conversations can and often do occur during care delivery, task-focused procedures and in the presence of others.

To be an effective receiver whilst delivering patient care requires personal insight, emotional self-control and a degree of vulnerability, that is a willingness to be wrong or to stand by your point of view or decision. Yet until now, it appears to have been expected that the receiver innately has the ability to understand and to respond reasonably and effectively in difficult and often challenging communication encounters. Thus, it is no surprise healthcare communication processes are failing. To be an effective receiver in the moment, when your decision, clinical skill and/or knowledge is being challenged, requires deliberate practice, just like learning a speaking-up algorithm. Additionally, what helps and hinders speaking-up behaviour is well documented but what is not known or studied is what helps or hinders the receiver hearing and respectfully responding to the speakingup message in the complex social and environmental healthcare context.

The impact of the receiver viewed through a validated theoretical lens is lacking in healthcare speaking-up research globally. Invoking theory provides a framework to understand and explain communicative behaviours of individuals and groups, and their attitudes and beliefs. It is crucial and timely to look beyond the skills of speaking up and, using a communication theory that acknowledges and accounts for the intergroup nature of healthcare, gain an understanding of the role the receiver plays.

SIT assists to understand intergroup dynamics and how group salience can differ depending on the situational context. What it does not provide is an understanding of what drives or motivates the communication behaviour of an individual in different 
contexts and what communication strategies are deployed to manage the intergroup communication dynamics.

\section{Communication accommodation theory}

Communication accommodation theory (CAT), founded in social psychology and underpinned by SIT, has now been utilised extensively in the healthcare context (Watson et al., 2016) but not yet in speaking up. CAT is well-suited to the study of speakingup behaviour in healthcare as it provides a validated method to identify and explain how people adjust their communication behaviour in different contexts (Gallois et al., 2015). It posits that each person comes to the [speaking-up] encounter with their own motivations and initial perceptions. These perceptions are influenced by the individual's professional memberships and associated traditional and/or cultural norms and values, interpersonal and intergroup history and social context. All factors will influence how each person communicates (Gallois et al., 2015). CAT describes how we affiliate or disaffiliate with the person we are communicating with by using specific communication strategies (emotional expression, discourse management, approximation, interpersonal control, interpretability) (Gallois et al., 2015). We use these strategies to either adjust our communication to meet the interactant's communication needs, facilitate comprehension and reduce the social distance between interactants (professional in-group and outgroup) or to increase social distance (non-accommodate) with the interactant to ensure the out-group remains salient (Gallois et al., 2015). In my example, the receiver did not accommodate my communication needs, instead using communication strategies to maintain and extend the social distance between our professional groups. This behaviour may not have been a conscious choice but, rather, a habitual or learned behaviour. By training receivers to be aware of and understand the impact of their communication behaviour choices and teaching them alternative strategies, individuals can begin deploying different and more accommodative communication strategies to enhance communication and, in turn, patient safety.

\section{What's next?}

CAT has the potential to enhance and expand speaking-up education by moving from a predominately competency-based approach to one that incorporates strategies to manage the intergroup, contextual and affectual factors that influence speaking-up conversations. This means not only educating the person speaking up but also training the receiver to effectively listen and respond in the moment and understand how their communication behaviour choices impact each interaction and future encounters. The application of CAT in healthcare speaking up is nascent, but its application as an education tool has enhanced communication in other contexts, such as pharmacology, dance and law enforcement (see Watson \& Soliz, 2018). 
The communication interaction I described impacted my confidence to speak up. It took many years for me to achieve the self-confidence to speak up until I was heard, despite undertaking speaking-up training. It took many more years until I gained theoretical insight into the intergroup nature of clinical care and how different professional groups deploy varying effective and ineffective communication strategies within a shared context. It should not take a defining moment like mine to achieve this level of understanding. We need to teach receivers how to utilise effective and accommodative communication strategies within the complex intergroup health environment. Through the utilisation of CAT, these insights can be gained.

My goal is to understand how receiver motivation, intention and language choice changes with varying intergroup context. By utilising a communication theory that appreciates the importance of context, training can move beyond generic speaking-up algorithms. The negative defining moment shared here has led me on my current journey to study speaking-up encounters from the receiver perspective. With more in-depth knowledge of receiver behaviour, speaking-up training will be enhanced and will ultimately create speaking-up journeys based on more positive defining moments.

\section{Acknowledgements}

Thank you to Prof Bernadette Watson, Prof Liz Jones, Assoc Prof Kate Morse and Dr Fiona MacCallum for your ongoing support and mentorship. It is greatly appreciated.

\section{Conflicts of interest and funding}

The author declares no conflicts of interest or funding.

\section{References}

Edmondson, A., Higgins, M., Singer, S., \& Weiner, J. (2016). Understanding psychological safety in health care and education organizations: A comparative perspective. Research in Human Development, 13(1), 65-83. https://doi.org/10.1080/1 5427609.2016.1141280

Gallois, C., Ogay, T., \& Giles, H. (2015). Communication accommodation theory: A look back and a look ahead. In W. B. Gudykunst (Ed.), The international encyclopedia of language and social interaction (pp. 121-118). Sage. https://doi. org/10.1002/9781118611463

Jones, A., Blake, J., Adams, M., Kelly, D., Mannion, R., \& Maben, J. (2021). Interventions promoting employee "speaking-up" within healthcare workplaces: A systematic narrative review of the international literature. Health Policy, 125(3), 375-384. https://doi.org/10.1016/j.healthpol.2020.12.016 
Jones, L., Sheeran, N., Lanyon, H., Evans, K., \& Martincovic, T. (2018). Nurses' perceptions of communicating with minority parents in a neonatal nursery: A communication accommodation theory approach. Journal of Communication in Healthcare, 11(3), 175-185. https://doi.org/10.1080/17538068.2018.1460959

Makary, M. A., \& Daniel, M. (2016). Medical error: The third leading cause of death in the US. BMJ, 353, i2139. https://doi.org/10.1136/bmj.i2139

Oyero, O. (2010). From"one-to-one" to "many-to-many": A new model of communication. In R. A. Akinfeleye (Ed.), Mass communication: A book of readings (pp. 14-31). Department of Mass Communication, University of Lagos.

Stone, D., \& Heen, S. (2015). Thanks for the feedback: The science and art of receiving feedback well. Penguin Books.

Tajfel, H. (1974). Social identity and intergroup behavior. Social Science Information, 13(2), 65-93. https://doi.org/10.1177/053901847401300204

Watson, B., Jones, L., Soliz, J., \& Gallois, C. (2016). Accommodating health. In H. Giles (Ed.), Communication accommodation theory: Negotiating personal relationships and social identities across contexts. Cambridge University Press. https://doi.org/10.1017/ CBO9781316226537

Watson, B., \& Soliz, J. (2018). Communication accommodation theory in institutional settings: Opportunities for applied research. In J. Harwood, J. Gasiorek, H. D. Pierson, J. F. Nussbaum, \& C. Gallois (Eds.), Language, communication, and intergroup relations: A celebration of the scholarship of Howard Giles (pp. 242-264). Routledge. https://doi.org/10.4324/9781315142807 